Article

\title{
Enhancement of the Antioxidant, Anti-Tyrosinase, and Anti-Hyaluronidase Activity of Morus alba L. Leaf Extract by Pulsed Electric Field Extraction
}

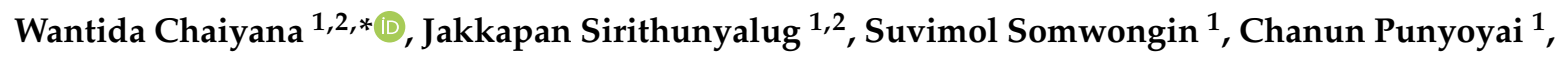 \\ Natnaree Laothaweerungsawat ${ }^{1}$, Pachabadee Marsup ${ }^{1}$, Waranya Neimkhum ${ }^{3}$ \\ and Artit Yawootti ${ }^{4}$ \\ 1 Department of Pharmaceutical Sciences, Faculty of Pharmacy, Chiang Mai University, \\ Chiang Mai 50200, Thailand; jakkapan.s@cmu.ac.th (J.S.); suvimol_ampoo@hotmail.com (S.S.); \\ spycooler_new@hotmail.com (C.P.); natnaree.la@gmail.com (N.L.); pch.marsup@gmail.com (P.M.) \\ 2 Research Center of Pharmaceutical Nanotechnology, Chiang Mai University, Chiang Mai 50200, Thailand \\ 3 Department of Pharmaceutical Technology, Faculty of Pharmaceutical Sciences, \\ Huachiew Chalermprakiet University, Samutprakarn 10250, Thailand; waranya.ne@gmail.com \\ 4 Department of Electrical Engineering, Faculty of Engineering, Rajamangala University of Technology Lanna, \\ Chiang Mai 50300, Thailand; yartit@rmutl.ac.th \\ * Correspondence: wantida.chaiyana@gmail.com; Tel.: +66-5394-4343
}

Received: 13 April 2020; Accepted: 6 May 2020; Published: 8 May 2020

check for updates

\begin{abstract}
In this study we aimed to compare the chemical composition and biological activity between Morus alba L. leaf extract obtained with 95\% v/v ethanol using a pulsed electric field (PEF) and the conventional maceration method. Extracts of M. alba leaves collected from Chiang Mai (CM), Sakon Nakon (SK), and Buriram (BR), Thailand, were investigated for 1-deoxynojirimycin content by high-performance liquid chromatography and for total phenolic content by the Folin-Ciocalteu method. Antioxidant activity was investigated by 2,2'-diphenyl-1-picrylhydrazyl (DPPH), 2,2'-azinobis -3-ethylbenzothiazoline-6-sulphonate (ABTS), and ferric reducing antioxidant power (FRAP) assay. Anti-tyrosinase and anti-hyaluronidase activity was investigated by in vitro spectrophotometry. The results show that this is the first study to indicate PEF as a novel method for enhancing the phenolic content and antioxidant, anti-tyrosinase, and anti-hyaluronidase activity of $M$. alba leaf extract $(P<0.05)$. PEF extract of $M$. alba leaves collected from BR had comparable ABTS ${ }^{\bullet+}$ scavenging activity to L-ascorbic acid and comparable anti-tyrosinase activity to kojic acid $(P>0.05)$. On the other hand, PEF extract of M. alba leaves collected from SK exhibited significantly high anti-hyaluronidase activity, comparable to that of oleanolic acid $(P>0.05)$. Therefore, PEF is suggested for further $M$. alba leaf extraction in the production of natural whitening and anti-aging cosmetic ingredients.
\end{abstract}

Keywords: Morus alba; pulsed electric field; antioxidant; anti-tyrosinase; anti-hyaluronidase; anti-aging

\section{Introduction}

Mulberry (Morus alba L.), belonging to the genus Morus in the family Moraceae, is widely distributed in various climatic conditions ranging from tropical to temperate [1]. The fruit of M. alba is edible and widely used in the preparation of juices, smoothies, desserts, jams, etc. Additionally, M. alba fruit has a long history of being used as a medicinal food in China to prevent premature graying of hair; nourish the blood and kidneys; and treat fatigue, weakness, dizziness, constipation, urinary incontinence, tinnitus, and anemia [2,3]. Various active biological components of M. alba fruit have been previously reported, including anthocyanins, rutin, quercetin, chlorogenic acid, and polysaccharides [1]. Other than the fruit, the leaf part has also been utilized, especially for feeding silkworms in Asian 
countries [4]. Moreover, M. alba leaf has been reported for its protection against age-related behavioral and biochemical changes, since it is rich in 1-deoxynojirimycin, an inhibitor of $\alpha$-glucosidase, which can alter cell surface glycosylation and plays an important role in protein turnover, tissue remodeling, diabetes, and skin aging [5-7]. Furthermore, cosmeceutical applications of M. alba leaf have also been proposed, since it possesses anti-aging, antioxidant, and anti-tyrosinase activity [8-10]. Therefore, developing an extraction technique that could enhance this cosmeceutical-related biological activity is attractive and worthwhile.

Pulsed electric field (PEF) is an application of high-voltage electric fields for brief periods of time into plant materials placed between two electrodes [11-13]. PEF promotes the modification of membrane permeability, known as electroporation or electropermeabilization, by which the mass transfer during extraction is enhanced [12,13]. PEF enhances a release of intracellular compounds from plant tissues and leads to increased extraction yield [12,13]. Additionally, PEF extraction has been reported as an economical process due to its relatively small power consumption [14]. PEF has been used for extraction of various natural compounds. Pretreatment with PEF has been reported to significantly increase the efficiency of betalain extraction from beetroot $(P<0.05)$ [11]. Additionally, a low pulse duration with a high pulse interval of PEF has been reported to increase the extraction efficiency of dry Moringa oleifera leaves [15]. PEF-assisted maceration of red grape juice also promoted wine color quality and the polyphenolic profile [16]. PEF also enhanced the extractability of carotenoids from various microalgae, including Chlorella vulgaris, Spirulina platensis, and Nannochloropsis sp. [17-22]. Furthermore, PEF has been defined as a green extraction technology because of its substantial minimization of toxic solvents, reduction of waste products, and lower energy consumption compared to conventional thermal extraction and dehydration processes [23-25].

Since PEF is an attractive method for extracting bioactive compounds from natural sources, the present study aimed to extract 1-deoxynojirimycin and phenolic compounds from $M$. alba leaves with 95\% $v / v$ ethanol using PEF extraction as cosmeceutical ingredients for topical application. In addition, the chemical composition and biological activity of $M$. alba leaf extract obtained by PEF were investigated in comparison with extract obtained by a conventional maceration method.

\section{Results and Discussion}

\subsection{M. alba Leaf Extracts}

The yield of M. alba leaf extract is shown in Figure 1. PEF yielded remarkably lower extract content than conventional maceration, due to different extraction duration and numbers of extraction cycles. It has been previously reported that an application of 300-1000 V/cm electric field strength and 100-1000 $\mu$ s pulse duration was efficient to allow permeabilization of plant tissue and usually improved the extraction yield [14,26]. However, in the present study, maceration was performed over $24 \mathrm{~h}$ for 3 cycles, while PEF was employed for only 20 min once. Therefore, longer extraction duration and more extraction cycles led to higher content yield since PEF generates electroporation, which leads to electropermeabilization and enhances mass transfer during extraction $[9,10]$. 


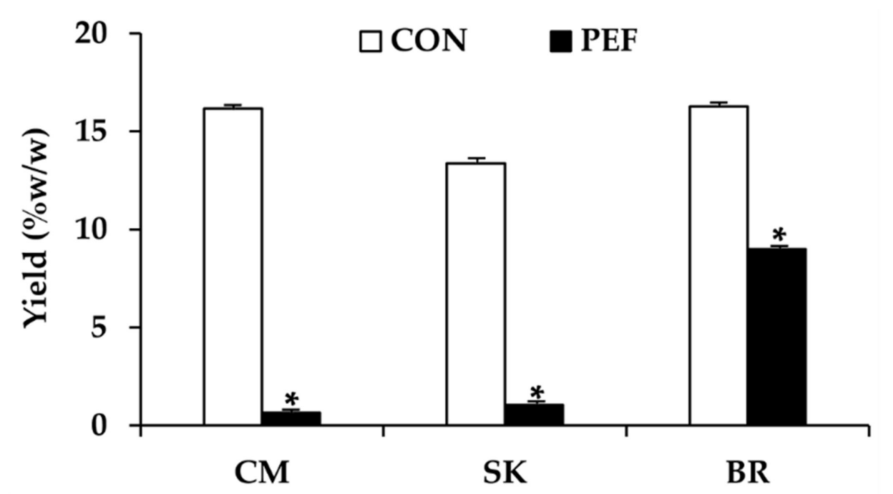

Figure 1. Yield of Morus alba leaf extract from Chiang Mai (CM), Sakon Nakon (SK), and Buriram (BR) when extracted using conventional maceration (CON) and pulsed electric field extraction (PEF). Asterisk ${ }^{*}$ ) denotes significant difference between $\mathrm{CON}$ and $\mathrm{PEF}, P<0.05$.

\subsection{Chemical Composition of M. alba Leaf Extracts}

M. alba leaf extract was investigated for 1-deoxynojirimycin and total phenolic content. HPLC chromatograms of 1-deoxynojirimycin and M. alba leaf extract are shown in Figure 2. A peak detected at $8.105 \mathrm{~min}$ on a chromatogram was in accordance with the 1-deoxynojirimycin peak detected at $8.064 \mathrm{~min}$. Internal standardization was already performed to confirm the 1-deoxynojirimycin peak. However, 1-deoxynojirimycin is not a major component of $M$. alba leaf extract, since it presented less than $1000 \mathrm{mg} / \mathrm{g}$ extract in all samples, as shown in Figure 3a. The conventional maceration method could extract significantly higher amounts of 1-deoxynojirimycin than PEF in all M. alba leaf extracts $(P<0.05)$. Therefore, PEF was not useful for extraction. Among various sources of $M$. alba leaves, SK yielded the highest 1-deoxynojirimycin content $(989.9 \pm 4.5 \mathrm{mg} / \mathrm{g}$ extract), followed by BR (369.9 \pm $0.2 \mathrm{mg} / \mathrm{g}$ extract$)$ and $\mathrm{CM}(575.9 \pm 3.1 \mathrm{mg} / \mathrm{g}$ extract). The 1-deoxynojirimycin content investigated in the present study related well with a previous report noting that most collected M. alba leaf samples contained $0.04-0.06 \%$ of 1-deoxynojirimycin content (equivalent to $400-600 \mathrm{mg} / \mathrm{g}$ extract) [27]. Various factors have been reported to affect the 1-deoxynojirimycin content in M. alba leaves, e.g., maturity of leaves, period of collection, species, and place of origin $[27,28]$. Since these factors were the same in the present study, place of origin might be a factor that affects the chemical composition and biological activity of $M$. alba leaf extract. The likely explanation is that it might be due to variations in climate, geography, and soil quality in each region. The climate of each region was a bit different. The annual temperature in $\mathrm{CM}$ (mean $26^{\circ} \mathrm{C}$, $\min 14^{\circ} \mathrm{C}$, max $39^{\circ} \mathrm{C}$ ) was lower than that in $\mathrm{BR}$ (mean $27^{\circ} \mathrm{C}$, $\min 22^{\circ} \mathrm{C}$, $\max 32{ }^{\circ} \mathrm{C}$ ) and SK (mean $27^{\circ} \mathrm{C}$, $\min 15^{\circ} \mathrm{C}$, max $39^{\circ} \mathrm{C}$ ) [29-32]. Additionally, most of $\mathrm{BR}$ and SK is plateau tablelands, whereas $\mathrm{CM}$ is mostly mountains and groves. On the other hand, there are volcanic soils, which are suitable for agriculture, in some regions of BR.

In contrast to 1-deoxynojirimycin content, PEF could extract significantly higher phenolic content from M. alba leaves compared to the conventional maceration method, as shown in Figure $3 b$, although the extraction duration was much shorter. Therefore, PEF was suggested as a high efficiency method for extraction of phenolic compounds. It was remarked that only $20 \mathrm{~min}$ of PEF extraction could be compared to 3 days of conventional maceration. M. alba leaves from BR extracted by PEF had the highest phenolic content $(71.5 \pm 0.9 \mathrm{mg}$ gallic acid/g extract), followed by SK $(54.9 \pm 0.4 \mathrm{mg}$ gallic acid/g extract) and CM (53.9 $\pm 2.1 \mathrm{mg}$ gallic acid/g extract). The high phenolic content of PEF extract of M. alba leaves from BR could support its remarkably higher yields very well. Therefore, it could be seen that more extracted phenolic compounds resulted in higher yield. Additionally, PEF was previously reported to enhance phenolic concentration in extracts of orange [33], grape [34], sorghum [35], apple [35], onion [36], spearmint [37], etc. According to the non-thermal technology of $\mathrm{PEF}$, it causes less degradation of chemical compounds in natural products compared to the conventional thermal process hence is used as an alternative to prevent thermolabile compound degradation during dehydration processes [38,39]. However, high voltage of PEF has been reported to increase degradation 
of some natural products, including phenolics. As phenolics donate electrons to other compounds, they respond to the alternate electric field [40]. Nevertheless, degradation was detected only by the thermal effect [40]. Therefore, suitable conditions of PEF would result in enhanced extraction efficiency without degradation of biological compounds.

\section{(a)}

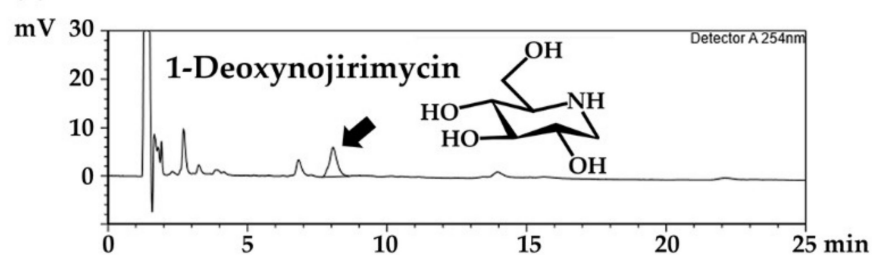

(b)

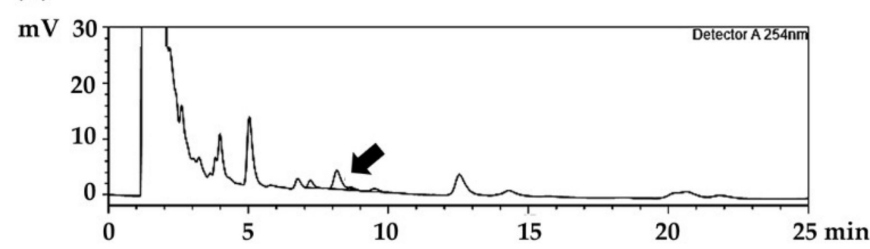

Figure 2. HPLC chromatograms of (a) 1-deoxynojirimycin and (b) M. alba leaf extract.

PEF was more suitable for extraction of phenolic compounds than 1-deoxynojirimycin, which has been widely known as an $\alpha$-glucosidase inhibitor used for diabetes mellitus [41]. PEF extracts were suitable for further development as cosmeceutical products rather than nutraceutical products since phenolics have been widely used in the cosmetics industry [42].
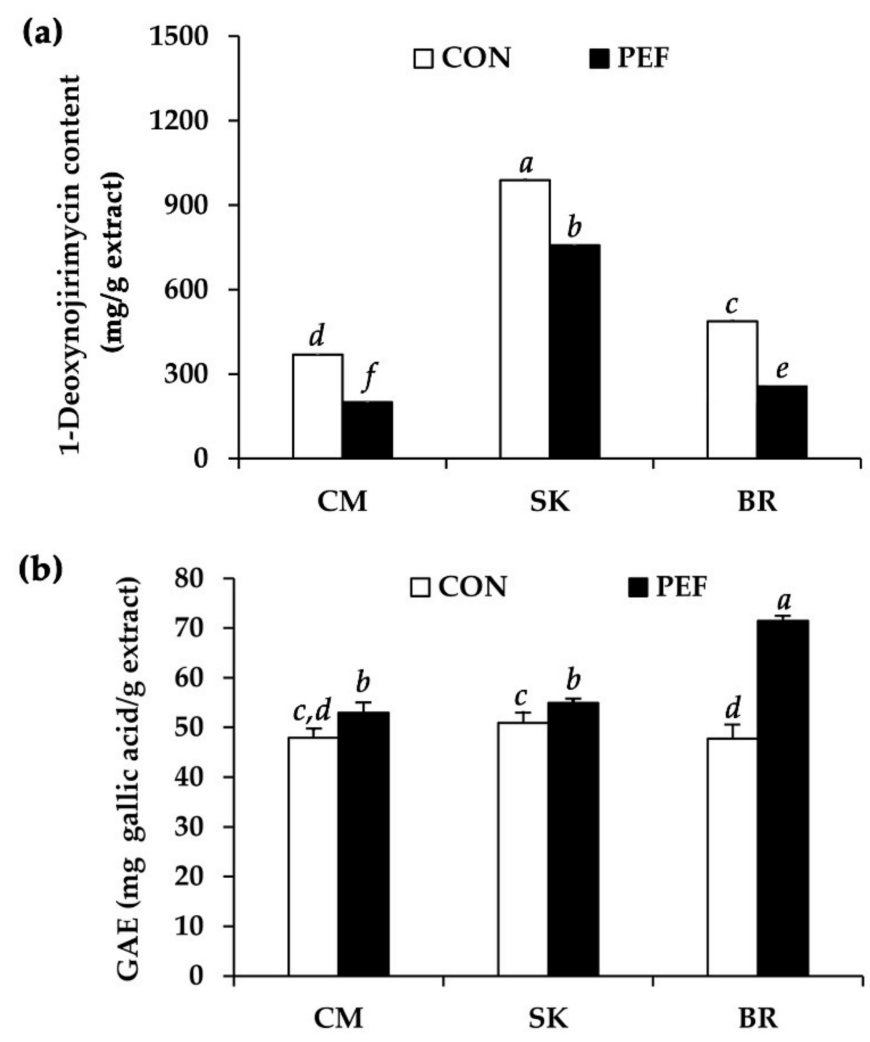

Figure 3. (a) 1-Deoxynojirimycin content and (b) total phenolic content, expressed as gallic acid equivalent (GAE), of M. alba leaf extract from Chiang Mai (CM), Sakon Nakhon (SK), and Buriram (BR). $a, b, c, d, e, f$ denote significant differences among samples in each experiment, $P<0.05$. 


\subsection{Antioxidant Activity of M. alba Leaf Extract}

Antioxidant activity of M. alba leaf extract is shown in Figure 4. All extract obtained by PEF had significantly higher radical scavenging activity compared to the conventional maceration method $(P<0.05)$. On the other hand, only $M$. alba leaves from BR had significantly higher ferric reducing antioxidant power $(P<0.05)$. Among different extracts, the PEF extract from BR had the highest inhibitory activity against $\mathrm{DPPH}^{\bullet}$ and $\mathrm{ABTS}^{\bullet+}$ and the highest ferric reducing antioxidant power with $\mathrm{DPPH}^{\bullet}$ inhibition of $45.3 \pm 0.8 \%$, Trolox equivalent antioxidant capacity (TEAC) value of $115.1 \pm 2.8$ $\mathrm{mg}$ Trolox/g extract, and $\mathrm{EC}_{1}$ value of $52.4 \pm 0.5 \mathrm{mg} \mathrm{FeSO} / \mathrm{g}$ extract $(P<0.05)$. The likely explanation might be the high phenolic content, since phenolics have been shown to have potent antioxidant activity and are usually responsible for the antioxidant activity of several natural extracts [43].
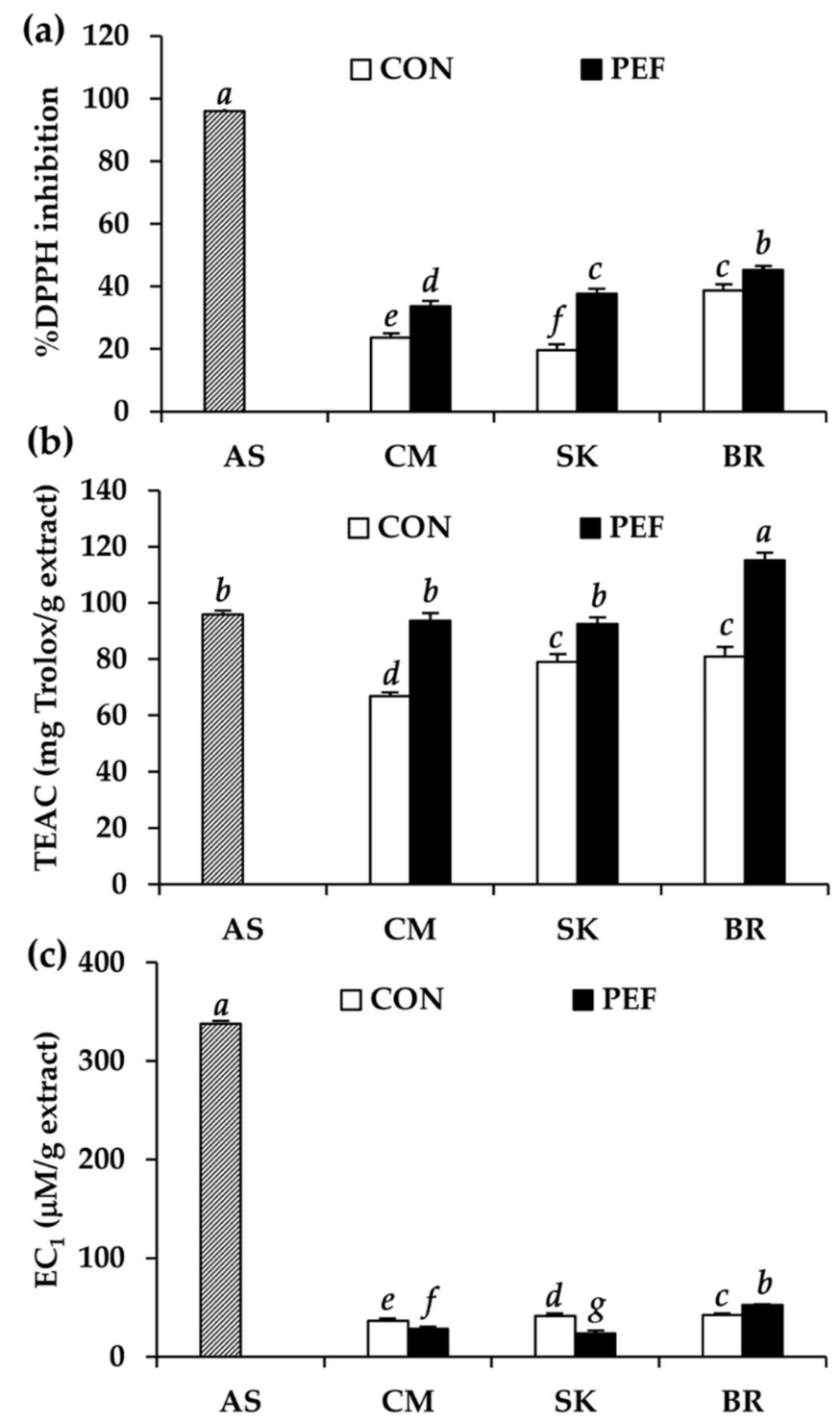

Figure 4. (a) $\mathrm{DPPH}^{\bullet}$ inhibition, (b) $\mathrm{ABTS}^{\bullet+}$ inhibition, and (c) ferric reducing antioxidant power of ascorbic acid (AS) and M. alba leaf extract from Chiang Mai (CM), Sakon Nakhon (SK), and Buriram (BR) expressed as \% inhibition, Trolox equivalent antioxidant capacity (TEAC), and equivalent concentration $\left(\mathrm{EC}_{1}\right) . a, b, c, d, e, f, g$ denote significant differences among samples in each experiment, $P<0.05$.

Interestingly, all PEF extracts had comparable or even higher ABTS ${ }^{\bullet+}$ scavenging activity compared to ascorbic acid, a commonly used antioxidant in the food, pharmaceutical, and cosmetic industries 
$(P>0.05)$. Therefore, PEF extract, especially from BR, was suggested as a potent natural antioxidant via the radical scavenging mechanism. Excessive production of reactive oxygen species (ROS) in the human body leads to oxidative stress, resulting in cell damage and cell death [44]. In addition, oxidative stress occurring in the skin plays a major role in the aging process and leads to wrinkles [45]. Therefore, radical scavengers, which have the ability to sacrificially reduce ROS formation and break down the oxidative chain reaction, finally prevent biomolecular damage $[46,47]$. Therefore, antioxidants have been widely used in cosmetic products as anti-aging components [48,49]. PEF extract from $\mathrm{BR}$, which had the most potent radical scavenging activity, would be an attractive natural anti-aging component in further cosmetic/cosmeceutical product development.

\subsection{Anti-Tyrosinase Activity of M. alba Leaf Extract}

The anti-tyrosinase activity of M. alba leaf extract is shown in Figure 5. Since tyrosinase plays a key role in melanin biosynthesis, natural extracts that have an inhibitory effect on melanin formation would be a good choice for the cosmetic purpose of whitening the skin [50]. All PEF extracts had a significantly more potent whitening effect than conventional crude extracts $(P<0.05)$. Although M. alba leaves have previously been shown to have a strong tyrosinase inhibitory effect, with inhibition comparable to arbutin [51], the present study is the first to highlight PEF as a novel extraction method to enhance anti-tyrosinase activity. Among different M. alba leaf extracts, PEF extract from BR exhibited the highest anti-tyrosinase activity, with $\mathrm{IC}_{50}$ values against tyrosinase activity on $\mathrm{L}$-tyrosine and L-DOPA of $54.1 \pm 5.4$ and $32.2 \pm 3.4 \mu \mathrm{g} / \mathrm{mL}$, respectively $(P<0.05)$. Interestingly, PEF extract from BR exhibited comparable anti-tyrosinase activity to kojic acid, with an $\mathrm{IC}_{50}$ value of $28.0 \pm 5.1 \mu \mathrm{g} / \mathrm{mL}$ when the substrate was L-DOPA $(P>0.05)$. Polyphenols have been reported as components responsible for depigmentation properties of $M$. alba leaves [50]. Therefore, it can be noted that PEF is an extraction method capable of enhancing phenolic extraction from $M$. alba leaves, resulting in an extract with a potent whitening effect.

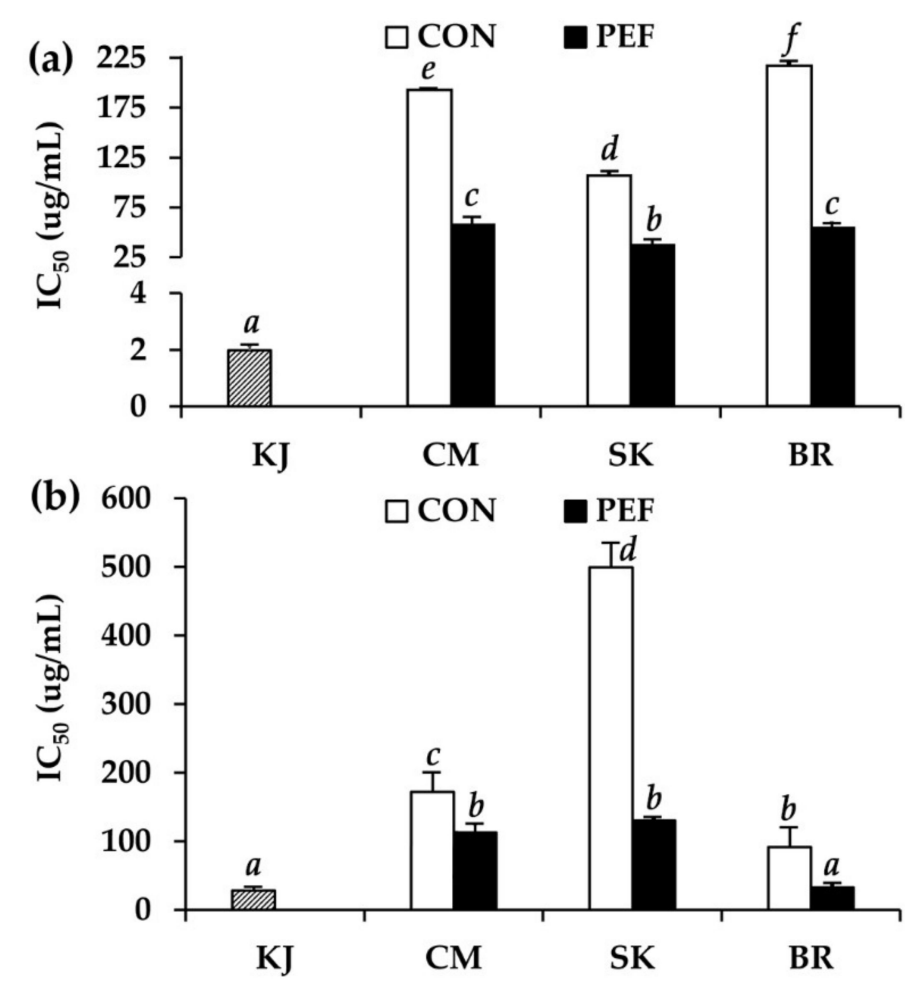

Figure 5. $\mathrm{IC}_{50}$ against tyrosinase with substrates (a) L-tyrosine and (b) L-DOPA of kojic acid (KJ) M. alba leaf extract from Chiang Mai (CM), Sakon Nakhon (SK), and Buriram (BR). $a, b, c, d, e, f$ denote significant differences among samples in each experiment, $P<0.05$. 


\subsection{Anti-Hyaluronidase Activity of M. alba Leaf Extract}

Hyaluronic acid (also called hyaluronan) is an essential component of the extracellular matrix of the skin that has some elastic properties [51]. However, it can be degraded into smaller fragments by hyaluronidases, which hydrolyze the disaccharides at the hexosaminidic $\beta(1-4)$ linkages, and the progressive loss of dermal hyaluronic acid is one of the hallmarks of skin aging [51]. Inhibition of hyaluronidase activity would thus be another way to retard the skin aging process.

The anti-hyaluronidase activity of $M$. alba leaf extract is shown in Figure 6. Conventional crude M. alba leaf extract demonstrated mild to moderate anti-hyaluronidase activity. PEF extraction significantly enhanced the anti-hyaluronidase activity of $M$. alba leaf extract. Interestingly, PEF extract from SK showed the highest anti-hyaluronidase activity (inhibition $=83.6 \pm 9.1 \%$ ), which was comparable to that of oleanolic acid (inhibition $=81.3 \pm 2.9 \%)(P>0.05)$. Therefore, $M$. alba leaf extract, which potentially inhibits hyaluronidase, would be an attractive natural anti-aging agent.

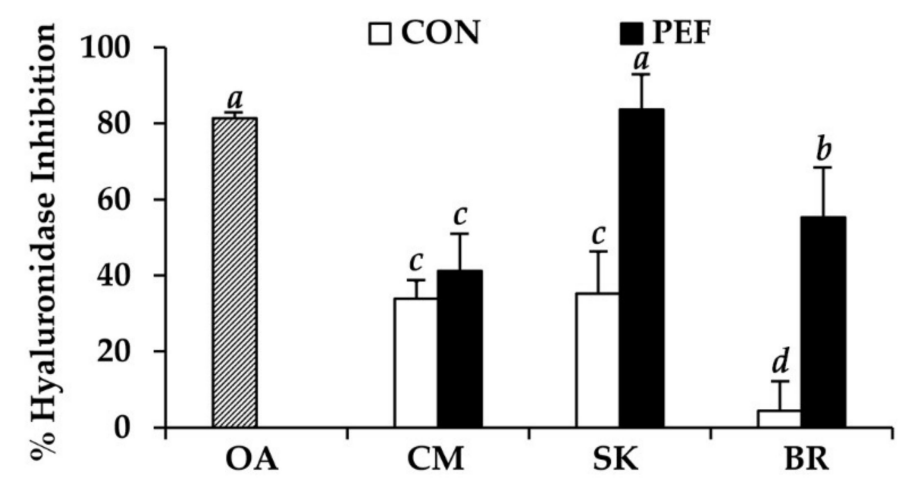

Figure 6. Hyaluronidase inhibitory activity of oleanolic acid (OA) and M. alba leaf extract from Chiang Mai (CM), Sakon Nakhon (SK), and Buriram (BR). $a, b, c, d$ denote significant differences among samples in each experiment, $P<0.05$.

\section{Materials and Methods}

\subsection{Plant Materials}

Fresh, fully matured M. alba leaves were obtained during October 2018 from local farms in CM (northern region of Thailand), SK (upper northeastern region), and BR (lower northeastern region), as shown in Figure 7. The fresh leaves were washed with tap water to remove dirt and allowed to dry at room temperature overnight. Subsequently, $200 \mathrm{~g}$ of $M$. alba leaves from each location were further dried in an oven (UF110, Memert, Germany) at $40{ }^{\circ} \mathrm{C}$. The dried M. alba leaves were then ground into fine powder using a Moulinex DB81 blender (Moulinex, Paris, France) and kept in well-closed containers until further extraction.

\subsection{Chemical Materials}

Tyrosinase from mushroom lyophilized powder (EC 1.14.18.1), hyaluronidase from bovine testes (EC 3.2.1.35), gallic acid, kojic acid, Trolox, L-ascorbic acid, L-tyrosine, L-DOPA, trifluoroacetic acid, Folin-Ciocalteu reagent, 2,4,6 tripyridyl-s-triazine (TPTZ), 2,2'-diphenyl-1-picrylhydrazyl-hydrate (DPPH), and 2,2'-azinobis 3-ethylbenzothiazoline-6-sulphonate (ABTS) were purchased from Sigma-Aldrich (St. Louis, $\mathrm{MO}, \mathrm{USA})$. Ferrous sulfate $\left(\mathrm{FeSO}_{4}\right)$, sodium carbonate $\left(\mathrm{Na}_{2} \mathrm{CO}_{3}\right)$, sodium acetate $\left(\mathrm{CH}_{3} \mathrm{COONa}\right)$, acetic acid $\left(\mathrm{CH}_{3} \mathrm{COOH}\right)$, hydrochloric acid $(\mathrm{HCl})$, potassium persulfate $\left(\mathrm{K}_{2} \mathrm{~S}_{2} \mathrm{O}_{8}\right)$, sodium chloride $(\mathrm{NaCl})$, monosodium phosphate $\left(\mathrm{NaH}_{2} \mathrm{PO}_{4}\right)$, and disodium phosphate $\left(\mathrm{Na}_{2} \mathrm{HPO}_{4}\right)$ were purchased from RCI Labscan Co., Ltd. (Bangkok, Thailand). Bovine serum albumin, AR grade ethanol, and HPLC grade acetonitrile were purchased from Merck (Darmstadt, Germany). 


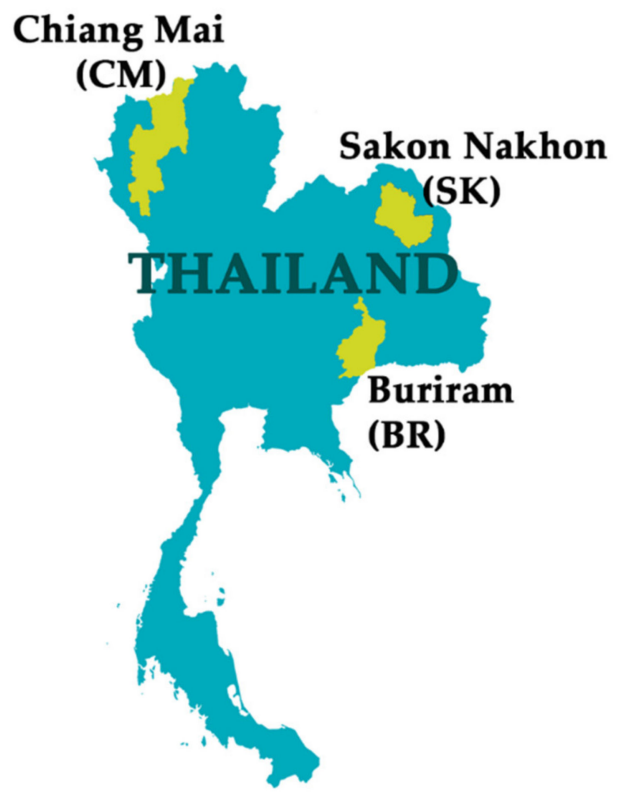

Figure 7. Source locations for M. alba leaves: Chiang Mai (CM), Sakon Nakon (SK), and Buriram (BR).

\subsection{Preparation of M. alba Leaf Extract}

\subsubsection{Maceration Method}

Dried powder of M. alba leaves was macerated in $95 \% v / v$ ethanol at a weight ratio of 1:5 for 3 cycles of $24 \mathrm{~h}$ each at room temperature. The $M$. alba leaf residue was removed by filtering through Whatman No. 1 filter paper. The solvent was subsequently removed from the collected filtrate by a rotary evaporator (Eyela, Tokyo, Japan) until dry. The extractions were performed in duplicate. The obtained conventional M. alba leaf extract was then used in further analyses.

\subsubsection{PEF Extraction Method}

Dried powder of M. alba leaves was macerated in $95 \% v / v$ ethanol at a weight ratio of 1:5 in a coaxial-cylindrical PEF chamber $(20 \mathrm{~mm}$ and $60 \mathrm{~mm}$ inner and outer electrode diameter, respectively, (Department of Electrical Engineering, Faculty of Engineering, Rajamangala University of Technology Lanna, Chiang Mai, Thailand). Both electrodes were stainless steel, with $300 \mathrm{~mL}$ capacity for containing plant materials. The inner electrode had $20 \mathrm{kV}$ for positive unipolar-exponential decay type, while the outer electrode was connected to ground. The PEF high voltage $(20 \mathrm{kV})$ was generated from the fly back circuit, which gets energy from the direct current (DC) switching power supply of $24 \mathrm{~V}$ and $200 \mathrm{~W}$. This high voltage was accumulated in the high-voltage capacitor and transmitted to the PEF treatment chamber by the rotating gap (Department of Electrical Engineering, Faculty of Engineering, Rajamangala University of Technology Lanna, Chiang Mai, Thailand). PEF treatment of $10 \mathrm{kV} / \mathrm{cm}$ was applied to the macerate at a frequency of $5 \mathrm{~Hz}$ with a pulse width of $1 \mu$ s for $20 \mathrm{~min}$, which had a total power consumption of about $0.6 \mathrm{kWh}$. The macerate was then filtered through Whatman No.1 filter paper. The solvent was subsequently removed from the collected filtrate by using a freeze dryer (Christ Beta 2-8 Ldplus, Martin Christ, Germany). The extractions were performed in triplicate. The obtained PEF M. alba leaf extract was then used in further analyses. 


\subsection{Determining Chemical Composition of M. alba Leaf Extract}

3.4.1. Determining 1-Deoxynojirimycin Content by High-Performance Liquid Chromatography (HPLC)

HPLC analysis was performed using an HP-1100 system (Hewlett Packard, Palo Alto, CA, USA). A reversed phase column (Eclipse XDB-C18, $150 \mathrm{~mm} \times 4.6 \mathrm{~mm}$ id, $5 \mu \mathrm{m}$; Agilent, Palo Alto, CA, USA) was connected with a guard column (Eclipse XDB-C18, $4.0 \mathrm{~mm} \times 4.6 \mathrm{~mm}$ id, $5 \mu \mathrm{m}$; Agilent, Palo Alto, CA, USA). An isocratic mobile phase system composed of acetonitrile and $0.1 \% v / v$ trifluoroacetic acid at a ratio of 45:55 was used to elute the sample at a flow rate of $1 \mathrm{~mL} / \mathrm{min}$. All samples were detected for UV absorbance (Hewlett Packard, Palo Alto, CA, USA) at $254 \mathrm{~nm}$. 1-Deoxynojirimycin was used as a marker for quantitative analysis. All experiments were performed in triplicate.

\subsubsection{Determining Total Phenolic Content}

Total phenolic content of each extract was investigated by the Folin-Ciocalteu method as previously described by Chaiyana et al. (2017) [52]. Briefly, $180 \mu \mathrm{L}$ of 1:10 diluted Folin-Ciocalteu reagent was added to $20 \mu \mathrm{L}$ of extract in a flat-bottomed 96-well UV plate (Costar, Corning Ltd., Sunderland, $\mathrm{UK}$ ) and incubated at room temperature in the dark for $4 \mathrm{~min}$. Subsequently, $80 \mu \mathrm{L}$ of $0.7 \mathrm{M}$ sodium carbonate solution was added, and it was further incubated at room temperature for $2 \mathrm{~h}$. The UV absorbance of the resulting mixture was measured at $750 \mathrm{~nm}$ using a multimode detector (Beckman Coulter DTX880, Fullerton, CA, USA). The standard curve was constructed using gallic acid $\left(\mathrm{R}^{2}=0.995\right)$. The concentration of phenolic compound, expressed as milligrams of gallic acid equivalent (GAE) per gram of extract, was calculated using Equation (1):

$$
\text { Total phenolic content (mg GAE per g extract) }=\frac{(A-B)-0.0095}{0.0061}
$$

where $A$ is absorbance of the mixture containing $20 \mu \mathrm{L}$ of sample solution, $180 \mu \mathrm{L}$ of Folin-Ciocalteu reagent, and $80 \mu \mathrm{L}$ of sodium carbonate solution, and $B$ is absorbance of the mixture containing $20 \mu \mathrm{L}$ of sample solution, $80 \mu \mathrm{L}$ of sodium carbonate solution, and $180 \mu \mathrm{L}$ of DI water. Three independent experiments repeated in triplicate were performed.

\subsection{Determining Antioxidant Activity}

\subsubsection{2,2'-Diphenyl-1-picrylhydrazyl-hydrate (DPPH) Assay}

Scavenging activity against DPPH radicals $\left(\mathrm{DPPH}^{\bullet}\right)$ of each extract was investigated using a DPPH assay according to a method previously described by Chaiyana et al. (2017) [52]. Briefly, $180 \mu \mathrm{L}$ of $167 \mu \mathrm{M}$ DPPH solution was added to $20 \mu \mathrm{L}$ of extract in a flat-bottomed 96-well UV plate (Costar, Corning Ltd., Sunderland, UK) and incubated at room temperature in the dark for $30 \mathrm{~min}$. The UV absorbance of the resulting mixture was measured at $520 \mathrm{~nm}$ using a multimode detector (Beckman Coulter DTX880, Fullerton, CA, USA). The DPPH` scavenging activity was calculated using Equation (2):

$$
\% \text { DPPH scavenging activity }=\left\{\frac{(A-B)-(C-D)}{A-B}\right\} 100
$$

where $A$ is UV absorbance of a mixture containing $20 \mu \mathrm{L}$ of DI water and $180 \mu \mathrm{L}$ of $167 \mu \mathrm{M}$ DPPH solution, $B$ is UV absorbance of a mixture containing $20 \mu \mathrm{L}$ of DI water and $180 \mu \mathrm{L}$ of absolute ethanol, $C$ is UV absorbance of a mixture containing $20 \mu \mathrm{L}$ of extract and $180 \mu \mathrm{L}$ of $167 \mu \mathrm{M}$ DPPH solution, and $D$ is UV absorbance of a mixture containing $20 \mu \mathrm{L}$ of extract and $180 \mu \mathrm{L}$ of absolute ethanol. $\mathrm{L}$-ascorbic acid was used as a positive control. Three independent experiments repeated in triplicate were performed. 


\subsubsection{2,2'-Azinobis 3-ethylbenzothiazoline-6-sulphonate (ABTS) Assay}

Scavenging activity against ABTS radicals $\left(\mathrm{ABTS}^{\bullet+}\right)$ of each extract was investigated using an ABTS assay according to a method previously described by Chaiyana et al. (2017) [52]. Briefly, $3 \mathrm{~mL}$ of $2.45 \mathrm{mM}$ potassium persulfate solution was mixed with $2 \mathrm{~mL}$ of $7 \mathrm{mM}$ ABTS solution and incubated in the dark for $24 \mathrm{~h}$. The resulting ABTS $^{\bullet+}$ solution was then diluted 20 times with ethanol. Then $180 \mu \mathrm{L}$ of the $\mathrm{ABTS}^{\bullet+}$ solution was added to $20 \mu \mathrm{L}$ of the sample solution in a flat-bottomed 96-well UV plate (Costar, Corning Ltd., Sunderland, UK) and incubated at room temperature for $5 \mathrm{~min}$. The UV absorbance of the resulting mixture was measured at $750 \mathrm{~nm}$ using a microplate reader (Spectrostar Nano, BMG Labtech GmbH, Ortenberg, Germany). The standard curve was constructed using Trolox $\left(\mathrm{R}^{2}=0.998\right)$. $\mathrm{ABTS}^{\bullet+}$ scavenging activity was expressed as Trolox equivalent antioxidant capacity (TEAC), representing the amount of Trolox $(\mathrm{mg})$ equivalent per $\mathrm{g}$ of sample. TEAC was calculated using Equation (3):

$$
\mathrm{TEAC}=\frac{(\mathrm{A}-\mathrm{B})-0.7615}{-0.0613}
$$

where $A$ is absorbance of the mixture containing $20 \mu \mathrm{L}$ of sample solution and $180 \mu \mathrm{L}$ of $\mathrm{ABTS}^{\bullet+}$ solution and $B$ is absorbance of the mixture containing $20 \mu \mathrm{L}$ of sample solution and $180 \mu \mathrm{L}$ of DI water. $\mathrm{L}$-ascorbic acid was used as a positive control. Three independent experiments repeated in triplicate were performed.

\subsubsection{Ferric Reducing Antioxidant Power (FRAP) Assay}

Ferric reducing antioxidant power of each extract was investigated using FRAP assay according to a method previously described by Chaiyana et al. (2017), which had been modified from Saeio et al. (2011) [52,53]. Briefly, FRAP solution was freshly prepared by mixing $10 \mathrm{~mL}$ of $0.3 \mathrm{M}$ acetate buffer

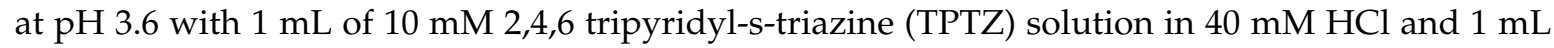
of $20 \mathrm{mM}$ ferric chloride. Subsequently, $180 \mu \mathrm{L}$ of the resulting FRAP solution was added to $20 \mu \mathrm{L}$ of each extract in a flat-bottomed 96-well UV plate (Costar, Corning Ltd., Sunderland, UK) and incubated at room temperature in the dark for $5 \mathrm{~min}$. The UV absorbance of the resulting mixture was measured at $595 \mathrm{~nm}$ using a multimode detector (Beckman Coulter DTX880, Fullerton, CA, USA). The standard curve was constructed using $\mathrm{FeSO}_{4}\left(\mathrm{R}^{2}=0.999\right)$. Ferric reducing power was expressed as equivalent capacity $\left(\mathrm{EC}_{1}\right)$, representing the amount $(\mu \mathrm{M})$ of $\mathrm{FeSO}_{4}$ equivalent per $\mathrm{g}$ of sample. $\mathrm{EC}_{1}$ was calculated using Equation (4):

$$
\mathrm{EC}_{1}=\frac{(\mathrm{A}-\mathrm{B})-0.0167}{0.1397}
$$

where $A$ is absorbance of the mixture containing $20 \mu \mathrm{L}$ of sample solution and $180 \mu \mathrm{L}$ of FRAP solution and $B$ is absorbance of the mixture containing $20 \mu \mathrm{L}$ of sample solution and $180 \mu \mathrm{L}$ of DI water. $\mathrm{L}$-ascorbic acid was used as a positive control. Three independent experiments repeated in triplicate were performed.

\subsection{Determining Anti-Tyrosinase Activity}

Each enzyme's inhibitory activity against tyrosinase was investigated using a spectrophotometric assay according to a method previously described by Laosirisathian et al. (2020), which had been modified from Pomerantz (1976) [54]. L-tyrosine and L-DOPA were used as substrates for the tyrosinase. Briefly, $90 \mu \mathrm{L}$ of 85 units/mL tyrosinase enzyme dissolved in PBS at pH 6.8 was added to $10 \mu \mathrm{L}$ of extract in a flat-bottomed 96-well UV plate (Costar, Corning Ltd., Sunderland, UK) and incubated at room temperature for $10 \mathrm{~min}$. Subsequently, $100 \mu \mathrm{L}$ of $2.5 \mathrm{mM}$ L-tyrosine or L-DOPA was added, and it was incubated at room temperature for a further $30 \mathrm{~min}$. The UV absorbance of the resulting 
mixture was measured at $450 \mathrm{~nm}$ using a multimode detector (Beckman Coulter DTX880, Fullerton, CA, USA). The anti-tyrosinase activity was calculated using Equation (5):

$$
\% \text { Antityrosinase activity }=\left\{\frac{(A-B)-(C-D)}{A-B}\right\} 100
$$

where $A$ is UV absorbance of a mixture containing $10 \mu \mathrm{L}$ of DI water, $90 \mu \mathrm{L}$ of tyrosinase enzyme, and $100 \mu \mathrm{L}$ of substrate; $B$ is UV absorbance of a mixture containing $10 \mu \mathrm{L}$ of DI water and $190 \mu \mathrm{L}$ of PBS at pH 6.8; $C$ is UV absorbance of a mixture containing $10 \mu \mathrm{L}$ of extract, $90 \mu \mathrm{L}$ of tyrosinase enzyme, and $100 \mu \mathrm{L}$ of substrate; and $D$ is UV absorbance of a mixture containing $10 \mu \mathrm{L}$ of extract and $190 \mu \mathrm{L}$ of PBS at $\mathrm{pH}$ 6.8. Kojic acid was used as a positive control. Various concentrations of sample, ranging from 6.25 to $100 \mu \mathrm{g} / \mathrm{mL}$, were investigated for percentage of tyrosinase inhibitory activity. Dose response curves of each sample were plot. $\mathrm{IC}_{50}$ value, which is a concentration at $50 \%$ tyrosinase inhibition, was then calculated using GraphPad Prism (version 2.01, GraphPad Software, San Diego, CA, USA). Three independent experiments repeated in triplicate were performed.

\subsection{Determining Anti-Hyaluronidase Activity}

The hyaluronidase inhibitory activity of each extract was investigated using spectrophotometric assay according to a method previously described by Chaiyana et al. (2019) with slight modifications [55]. First, 15 units/mL of hyaluronidase solution was prepared by dissolving hyaluronidase from bovine testes in $20 \mathrm{mM}$ phosphate buffer at $\mathrm{pH} 5.35$ containing $0.01 \% w / v$ BSA and $77 \mathrm{mM} \mathrm{NaCl}$. Subsequently, $100 \mu \mathrm{L}$ of hyaluronidase solution was added to $20 \mu \mathrm{L}$ of extract in a flat-bottomed 96-well UV plate (Costar, Corning Ltd., Sunderland, UK) and incubated at $37^{\circ} \mathrm{C}$ for $10 \mathrm{~min}$. Subsequently, $100 \mu \mathrm{L}$ of $0.03 \% w / v$ hyaluronic acid in phosphate buffer at $\mathrm{pH} 5.35$ was added, and it was further incubated at $37^{\circ} \mathrm{C}$ for $45 \mathrm{~min}$. The UV absorbance of the resulting mixture was measured at $600 \mathrm{~nm}$ using a multimode detector (Beckman Coulter DTX880, Fullerton, CA, USA). The hyaluronidase inhibitory activity was calculated using Equation (6):

$$
\% \text { Hyaluronidase activity }=\left\{\frac{(A-B)-(C-D)}{A-B}\right\} 100
$$

where $A$ is UV absorbance of a mixture containing $20 \mu \mathrm{L}$ of DI water, $100 \mu \mathrm{L}$ of hyaluronidase solution, and $100 \mu \mathrm{L}$ of hyaluronic acid solution; $B$ is UV absorbance of a mixture containing $20 \mu \mathrm{L}$ of DI water and $200 \mu \mathrm{L}$ of phosphate buffer at $\mathrm{pH} 5.35 ; \mathrm{C}$ is UV absorbance of a mixture containing $20 \mu \mathrm{L}$ of extract, $100 \mu \mathrm{L}$ of hyaluronidase solution, and $100 \mu \mathrm{L}$ of hyaluronic acid solution; and $C$ is $\mathrm{UV}$ absorbance of a mixture containing $20 \mu \mathrm{L}$ of extract and $200 \mu \mathrm{L}$ of phosphate buffer at $\mathrm{pH}$ 5.35. Oleanolic acid was used as a positive control. Three independent experiments repeated in triplicate were performed.

\subsection{Statistical Analysis}

All data are presented as a mean \pm standard deviation (SD). Statistical significance was analyzed by one-way analysis of variance (ANOVA) followed by Tukey's post-hoc test using SPSS 17.0 for Windows (SPSS Inc., Chicago, IL, USA). $P<0.05$ was considered statistically significant.

\section{Conclusions}

The present study is the first to highlight PEF as an extraction method capable of enhancing phenolic content in M. alba leaf extract. In addition, PEF significantly enhanced antioxidant, anti-tyrosinase, and anti-hyaluronidase activity of $M$. alba leaf extract $(P<0.05)$. Although there are many articles dealing with PEF extraction, most of them are aimed at using PEF in the food industry. There are only a few studies dealing with cosmetic applications. The present study is hence the first to reveal the potential of PEF extraction to enhance the variety of cosmetic activities of $M$. alba leaves for use in the cosmetic industry. However, the location where M. alba leaves were collected had an effect 
on their biological activity. PEF extract of leaves collected from BR contained the highest phenolic content and also exhibited the highest radical scavenging activity, ferric reducing antioxidant power, and anti-tyrosinase activity $(P<0.05)$. Its $\mathrm{ABTS}^{\bullet+}$ scavenging activity was comparable to that of L-ascorbic acid and its anti-tyrosinase activity was comparable to that of kojic acid $(P>0.05)$. In addition, this study is also the first to report anti-hyaluronidase activity of $M$. alba leaves. The PEF extract of leaves collected from SK had the highest anti-hyaluronidase activity, which was comparable to that of oleanolic acid $(P>0.05)$. PEF not only could enhance the variety of cosmetic activities of $M$. alba leaves, but also is a green extraction method, which could minimize the consumption of organic solvent and energy and the duration of extraction. Therefore, PEF is suggested for further use for the production of M. alba leaf extract, which is an attractive natural whitening and anti-aging agent. Additionally, a further microscopic study is suggested to understand the mechanism and effects of PEF extraction.

Author Contributions: Conceptualization, W.C.; methodology, W.C., J.S., and A.Y.; validation, W.C., J.S., and A.Y.; formal analysis, W.C., S.S., C.P., N.L., P.M., and W.N.; investigation, W.C., S.S., C.P., N.L., P.M., and W.N.; resources, W.C., J.S., and A.Y.; writing-original draft preparation, W.C. and A.Y.; writing-review and editing, W.C., J.S., S.S., C.P., N.L., P.M., W.N., and A.Y.; supervision, W.C. and J.S.; project administration, W.C. and J.S.; funding acquisition, J.S. All authors have read and agreed to the published version of the manuscript.

Funding: This research was funded by the National Research Council of Thailand.

Acknowledgments: We would like to acknowledge and thank Prof. Dr. Sermkiat Jomjunyong, Department of Industrial Engineering, Faculty of Engineering, Chiang Mai University, Thailand, for support with M. alba leaf materials.

Conflicts of Interest: The authors declare no conflict of interest.

\section{References}

1. Yuan, Q.; Zhao, L. The Mulberry (Morus alba L.) Fruit—A Review of Characteristic Components and Health Benefits. J. Agric. Food Chem. 2017, 65, 10383-10394. [CrossRef] [PubMed]

2. Devi, B.; Sharma, N.; Kumar, D.; Jeet, K. Morus alba Linn: A phytopharmacological review. Int. J. Pharm. Pharm. Sci. 2013, 5, 14-18.

3. Qin, C.; Li, Y.; Niu, W.; Ding, Y.; Zhang, R.; Shang, X. Analysis and characterisation of anthocyanins in mulberry fruit. Czech J. Food Sci. 2010, 28, 117-126. [CrossRef]

4. Khamenei-Tabrizi, A.S.; Sendi, J.J.; Imaani, S.; Shojaee, M. Can Feeding of Silkworm on Different Mulberry Variety Affect Its Performance? J. Econ. Entomol. 2020, 113, 281-287. [CrossRef]

5. Chen, G.H.; Tong, J.J.; Wang, F.; Hu, X.Q.; Li, X.W.; Tao, F.; Wei, Z.J. Chronic adjunction of 1-deoxynojirimycin protects from age-related behavioral and biochemical changes in the SAMP8 mice. Age 2015, 37, 102. [CrossRef]

6. Wang, R.J.; Yang, C.H.; Hu, M.L. 1-Deoxynojirimycin inhibits metastasis of B16F10 melanoma cells by attenuating the activity and expression of matrix metalloproteinases-2 and-9 and altering cell surface glycosylation. J. Agric. Food Chem. 2010, 58, 8988-8993. [CrossRef]

7. Jeanmaire, C.; Danoux, L.; Pauly, G. Glycation during human dermal intrinsic and actinic ageing: An in vivo and in vitro model study. Br. J. Derm. 2001, 145, 10-18. [CrossRef] [PubMed]

8. Chang, L.W.; Juang, L.J;; Wang, B.S.; Wang, M.Y.; Tai, H.M.; Hung, W.J.; Chen, Y.J.; Huang, M.H. Antioxidant and antityrosinase activity of mulberry (Morus alba L.) twigs and root bark. Food Chem. Toxicol. 2011, 49, 785-790. [CrossRef]

9. Iqbal, S.; Younas, U.; Chan, K.W.; Sarfraz, R.A.; Uddin, M. Proximate composition and antioxidant potential of leaves from three varieties of Mulberry (Morus sp.): A comparative study. Int. J. Mol. Sci. 2012, 13, 6651-6664. [CrossRef]

10. Park, S.; Kim, Y.S.; Lee, H.A.; Lim, Y.; Kim, Y. Mulberry Leaf Extract Inhibits Invasive Potential and Downregulates Hypoxia-Inducible Factor- $1 \alpha$ (HIF-1 $\alpha$ ) in SK-N-BE (2) C Neuroblastoma Cells. Biosci. Biotechnol. Biochem. 2013, 2013, 120763. [CrossRef]

11. Nowacka, M.; Tappi, S.; Wiktor, A.; Rybak, K.; Miszczykowska, A.; Czyzewski, J.; Drozdzal, K.; Witrowa-Rajchert, D.; Tylewicz, U. The Impact of Pulsed Electric Field on the Extraction of Bioactive Compounds from Beetroot. Foods 2019, 8, 244. [CrossRef] 
12. Mannozzi, C.; Rompoonpol, K.; Fauster, T.; Tylewicz, U.; Romani, S.; Dalla Rosa, M.; Jaeger, H. Influence of Pulsed Electric Field and Ohmic Heating Pretreatments on Enzyme and Antioxidant Activity of Fruit and Vegetable Juices. Foods 2019, 8, 247. [CrossRef] [PubMed]

13. Zbinden, M.D.A.; Sturm, B.S.; Nord, R.D.; Carey, W.J.; Moore, D.; Shinogle, H.; Stagg-Williams, S.M. Pulsed electric field (PEF) as an intensification pretreatment for greener solvent lipid extraction from microalgae. Biotechnol. Bioeng. 2013, 110, 1605-1615. [CrossRef] [PubMed]

14. Parniakov, O.; Lebovka, N.I.; Van Hecke, E.; Vorobiev, E. Pulsed electric field assisted pressure extraction and solvent extraction from mushroom (Agaricus bisporus). Food Bioprocess Tech. 2014, 7, 174-183. [CrossRef]

15. Bozinou, E.; Karageorgou, I.; Batra, G.; Dourtoglou, V.G.; Lalas, S.I. Pulsed electric field extraction and antioxidant activity determination of Moringa oleifera dry leaves: A comparative study with other extraction techniques. Beverages 2019, 5, 8. [CrossRef]

16. Ricci, A.; Parpinello, G.P.; Versari, A. Recent advances and applications of pulsed electric fields (PEF) to improve polyphenol extraction and color release during red winemaking. Beverages 2018, 4, 18. [CrossRef]

17. Poojary, M.M.; Barba, F.J.; Aliakbarian, B.; Donsì, F.; Pataro, G.; Dias, D.A.; Juliano, P. Innovative alternative technologies to extract carotenoids from microalgae and seaweeds. Mar. Drugs. 2016, 14, 214. [CrossRef]

18. Grimi, N.; Dubois, A.; Marchal, L.; Jubeau, S.; Lebovka, N.I.; Vorobiev, E. Selective extraction from microalgae Nannochloropsis sp. using different methods of cell disruption. Bioresour. Technol. 2014, 153, 254-259. [CrossRef]

19. Luengo, E.; Martínez, J.M.; Bordetas, A.; Álvarez, I.; Raso, J. Influence of the treatment medium temperature on lutein extraction assisted by pulsed electric fields from Chlorella vulgaris. Innov. Food Sci. Emerg. Technol. 2015, 29, 15-22. [CrossRef]

20. Luengo, E.; Condón-Abanto, S.; Álvarez, I.; Raso, J. Effect of pulsed electric field treatments on permeabilization and extraction of pigments from Chlorella vulgaris. J. Membr. Biol. 2014, 247, 1269-1277. [CrossRef]

21. Parniakov, O.; Barba, F.J.; Grimi, N.; Marchal, L.; Jubeau, S.; Lebovka, N.; Vorobiev, E. Pulsed electric field and $\mathrm{pH}$ assisted selective extraction of intracellular components from microalgae Nannochloropsis. Algal. Res. 2015, 8, 128-134. [CrossRef]

22. Grosso, C.; Valentão, P.; Ferreres, F.; Andrade, P.B. Alternative and efficient extraction methods for marine-derived compounds. Mar. Drugs. 2015, 13, 3182-3230. [CrossRef] [PubMed]

23. Poojary, M.M.; Lund, M.N.; Barba, F.J. Pulsed electric field (PEF) as an efficient technology for food additives and nutraceuticals development. In Pulsed Electric Fields to Obtain Healthier and Sustainable Food for Tomorrow; Francisco, J.B., Oleksii, P., Artur, W., Eds.; Elsevier Inc.: London, UK, 2020; pp. 65-100. [CrossRef]

24. Barba, F.J.; Roselló-Soto, E.; Marszałek, K.; Kovačević, D.B.; Jambrak, A.R.; Lorenzo, J.M.; Chemat, F.; Putnik, P. Green food processing: Concepts, strategies, and tools. In Green Food Processing Techniques; Chemat, F., Vorobiev, E., Eds.; Academic Press: Cambridge, MA, USA, 2019; pp. 1-21. [CrossRef]

25. Prabhu, M.S.; Levkov, K.; Livney, Y.D.; Israel, A.; Golberg, A. High-Voltage Pulsed Electric Field Preprocessing Enhances Extraction of Starch, Proteins, and Ash from Marine Macroalgae Ulva ohnoi. Acs Sustain. Chem. Eng. 2019, 7, 17453-17463. [CrossRef]

26. Boussetta, N.; Vorobiev, E.; Le, L.H.; Cordin-Falcimaigne, A.; Lanoisellé, J.L. Application of electrical treatments in alcoholic solvent for polyphenols extraction from grape seeds. LWT-Food Sci. Technol. 2012, 46, 127-134. [CrossRef]

27. Yatsunami, K.; Ichida, M.; Onodera, S. The relationship between 1-deoxynojirimycin content and $\alpha$-glucosidase inhibitory activity in leaves of 276 mulberry cultivars (Morus spp.) in Kyoto, Japan. J. Nat. Med. 2008, 62, 63-66. [CrossRef] [PubMed]

28. Hu, X.Q.; Jiang, L.; Zhang, J.G.; Deng, W.; Wang, H.L.; Wei, Z.J. Quantitative determination of 1-deoxynojirimycin in mulberry leaves from 132 varieties. Ind. Crop. Prod. 2013, 49, 782-784. [CrossRef]

29. Boonprong, M. Public policy with promotion to Thai swamp buffaloes production: A case study on raising Thai swamp buffaloes and satisfaction of local farmers in Buriram province, Thailand. In AFBE 2014 conference paper, Proceedings of AFBE 2014 conference paper, Thaksin University, Thailand, 5-6 November 2014; Thaksin University: Songkhla, Thailand, 2014.

30. Sriprom, M.; Chalvet-Monfray, K.; Chaimane, T.; Vongsawat, K.; Bicout, D.J. Monthly district level risk of dengue occurrences in Sakon Nakhon Province, Thailand. Sci. Total Env. 2010, 408, 5521-5528. [CrossRef] 
31. Doi, R.; Itoh, M.; Chakhatrakan, S.; Uga, S. Epidemiological investigation of parasitic infection of schoolchildren from six elementary schools in Sakon Nakhon Province, Thailand. Kobe J. Med. Sci. 2016, 62, E120.

32. Tangtrongsup, S.; Scorza, A.V.; Reif, J.S.; Ballweber, L.R.; Lappin, M.R.; Salman, M.D. Seasonal distributions and other risk factors for Giardia duodenalis and Cryptosporidium spp. infections in dogs and cats in Chiang Mai, Thailand. Prev. Vet. Med. 2020, 174, 104820. [CrossRef]

33. Agcam, E.; Akyıldız, A.; Evrendilek, G.A. Comparison of phenolic compounds of orange juice processed by pulsed electric fields (PEF) and conventional thermal pasteurisation. Food Chem. 2014, 143, 354-361. [CrossRef]

34. López-Giral, N.; González-Arenzana, L.; González-Ferrero, C.; López, R.; Santamaría, P.; López-Alfaro, I.; Garde-Cerdán, T. Pulsed electric field treatment to improve the phenolic compound extraction from Graciano, Tempranillo and Grenache grape varieties during two vintages. Innov. Food Sci. Emerg. Technol. 2015, 28, 31-39. [CrossRef]

35. Lohani, U.C.; Muthukumarappan, K. Application of the pulsed electric field to release bound phenolics in sorghum flour and apple pomace. Innov. Food Sci. Emerg. Technol. 2016, 35, 29-35. [CrossRef]

36. Liu, Z.W.; Zeng, X.A.; Ngadi, M. Enhanced extraction of phenolic compounds from onion by pulsed electric field (PEF). J. Food Process. Pres. 2018, 42, 13755. [CrossRef]

37. Fincan, M. Extractability of phenolics from spearmint treated with pulsed electric field. J. Food Eng. 2015, 162, 31-37. [CrossRef]

38. Bhat, Z.F.; Morton, J.D.; Mason, S.L.; Bekhit, A.E.D.A. Current and future prospects for the use of pulsed electric field in the meat industry. Crit. Rev. Food Sci. Nutr. 2019, 59, 1660-1674. [CrossRef] [PubMed]

39. Wiktor, A.; Singh, A.P.; Parniakov, O.; Mykhailyk, V.; Mandal, R.; Witrowa-Rajchert, D. PEF as an alternative tool to prevent thermolabile compound degradation during dehydration processes. In Pulsed Electric Fields to Obtain Healthier and Sustainable Food for Tomorrow; Francisco, J.B., Oleksii, P., Artur, W., Eds.; Elsevier Inc.: London, UK, 2020; pp. 155-202. [CrossRef]

40. Brochier, B.; Mercali, G.D.; Marczak, L.D.F. Effect of moderate electric field on peroxidase activity, phenolic compounds and color during ohmic heating of sugarcane juice. J. Food Process. Preserv. 2019, 43, 14254. [CrossRef]

41. Li, Y.G.; Ji, D.F.; Zhong, S.; Lv, Z.Q.; Lin, T.B.; Chen, S.; Hu, G.Y. Hybrid of 1-deoxynojirimycin and polysaccharide from mulberry leaves treat diabetes mellitus by activating PDX-1/insulin-1 signaling pathway and regulating the expression of glucokinase, phosphoenolpyruvate carboxykinase and glucose-6-phosphatase in alloxan-induced diabetic mice. J. Ethnopharmacol. 2011, 134, 961-970. [CrossRef]

42. Przybylska-Balcerek, A.; Stuper-Szablewska, K. Phenolic acids used in the cosmetics industry as natural antioxidants. EJMT 2019, 4, 24-32. Available online: http://www.medical-technologies.eu/upload/phenolic acids_-_przybylska.pdf (accessed on 12 April 2020).

43. Shahidi, F.; Ambigaipalan, P. Phenolics and polyphenolics in foods, beverages and spices: Antioxidant activity and health effects-A review. J. Funct. Foods. 2015, 18, 820-897. [CrossRef]

44. Poljšak, B.; Dahmane, R. Free radicals and extrinsic skin aging. Derm. Res. Pr. 2012, 2012, 135206. [CrossRef]

45. Rinnerthaler, M.; Bischof, J.; Streubel, M.K.; Trost, A.; Richter, K. Oxidative stress in aging human skin. Biomolecules 2015, 5, 545-589. [CrossRef] [PubMed]

46. Winterbourn, C.C. Biological chemistry of superoxide radicals. Chemtexts 2020, 6, 7. [CrossRef]

47. Igielska-Kalwat, J.; Gościańska, J.; Nowak, I. Carotenoids as natural antioxidants. Post. Hig. Med. Dosw. 2015, 69, 418-428. [CrossRef] [PubMed]

48. Silva, S.; Ferreira, M.; Oliveira, A.S.; Magalhaes, C.; Sousa, M.E.; Pinto, M.; Sousa Lobo, J.M.; Almeida, I.F. Evolution of the use of antioxidants in anti-ageing cosmetics. Int. J. Cos. Sci. 2019, 41, 378-386. [CrossRef]

49. Hanh, N.T.M.; Phung, N.K.P.; Phuong, Q.N.D. Studying on Tyrosinase Inhibition Activity of Some Vietnamese Folk Plants Aims to Use in Skin-Whitening Cosmetics. Am. J. Plant Sci. 2017, 8, 1319. [CrossRef]

50. Couteau, C.; Coiffard, L. Overview of skin whitening agents: Drugs and cosmetic products. Cosmetics 2016, 3, 27. [CrossRef]

51. Buhren, B.A.; Schrumpf, H.; Hoff, N.P.; Bölke, E.; Hilton, S.; Gerber, P.A. Hyaluronidase: From clinical applications to molecular and cellular mechanisms. Eur. J. Med. Res. 2016, 21, 5. [CrossRef] 
52. Chaiyana, W.; Punyoyai, C.; Somwongin, S.; Leelapornpisid, P.; Ingkaninan, K.; Waranuch, N.; Srivilai, J.; Thitipramote, N.; Wisuitiprot, W.; Schuster, R.; et al. Inhibition of $5 \alpha$-reductase, IL-6 secretion, and oxidation process of Equisetum debile Roxb. ex vaucher extract as functional food and nutraceuticals ingredients. Nutrients 2017, 9, 1105. [CrossRef]

53. Saeio, K.; Chaiyana, W.; Okonogi, S. Antityrosinase and antioxidant activities of essential oils of edible Thai plants. Drug Discov. 2011, 5, 144-149. [CrossRef]

54. Laosirisathian, N.; Saenjum, C.; Sirithunyalug, J.; Eitssayeam, S.; Sirithunyalug, B.; Chaiyana, W. The Chemical Composition, Antioxidant and Anti-Tyrosinase Activities, and Irritation Properties of Sripanya Punica granatum Peel Extract. Cosmetics 2020, 7, 7. [CrossRef]

55. Chaiyana, W.; Anuchapreeda, S.; Punyoyai, C.; Neimkhum, W.; Lee, K.H.; Lin, W.C.; Lue, S.C.; Viernstein, H.; Mueller, M. Ocimum sanctum Linn. as a natural source of skin anti-ageing compounds. Ind. Crops Prod. 2019, 127, 217-224. [CrossRef]

Sample Availability: Samples of M. alba leaf extracts are available from the authors.

(C) 2020 by the authors. Licensee MDPI, Basel, Switzerland. This article is an open access article distributed under the terms and conditions of the Creative Commons Attribution (CC BY) license (http://creativecommons.org/licenses/by/4.0/). 